\title{
Adipocytes induce the resistance of ovarian cancer to carboplatin through ANGPTL4
}

\author{
SONGHUI ZHOU ${ }^{1}$, RUICHENG WANG ${ }^{1}$ and HONG XIAO ${ }^{2}$ \\ ${ }^{1}$ Department of Pharmacy, Jiangsu Cancer Hospital and Jiangsu Institute of Cancer Research and \\ The Affiliated Cancer Hospital of Nanjing Medical University; ${ }^{2}$ Department of Pharmacy, \\ The Affiliated Brain Hospital of Nanjing Medical University, Nanjing, Jiangsu 210029, P.R. China
}

Received August 2, 2019; Accepted May 14, 2020

DOI: $10.3892 /$ or.2020.7647

\begin{abstract}
The resistance of cancer cells to carboplatin restricts their efficacy in the clinical setting, and a solution to reverse the resistance is urgently required for the treatment of ovarian cancer. An increasing number of studies have found associations between obesity and the incidence, and mortality rates of female cancer. However, the association between adipocytes and the resistance of ovarian cancer has rarely been reported. Based on this, the present study first revealed the inductive effect of adipocytes on the resistance of ovarian cancer to carboplatin using in vivo and in vitro experiments. Subsequently, it was identified that the angiopoietin-like 4 (ANGPTL4) secreted by adipocytes played a vital role in the resistance of ovarian cancer using bioinformatics analysis, cellular and molecular biological experiments, as well as forward and backward validation. The glycosylated ANGPTL 4 protein could bind with integrin $\alpha 5 \beta 1$ on the surface of ovarian cancer cells; following which, it could activate the $c-m y c / N F-\kappa B$ pathway and stimulate the expression of the antiapoptotic protein Bcl-xL, as well as the ABC transporter family members ABCB1, ABCC1 and ABCG2. Thus, inducing the resistance of ovarian cancer to carboplatin. In conclusion, targeting the adipocyte-derived ANGPTL4 combined with the application of carboplatin contributes to the clinical treatment for ovarian cancer.
\end{abstract}

\section{Introduction}

Ovarian cancer is a common malignant tumor in females (1). According to the 2018 Global Cancer Statistics, the morbidity rate of ovarian cancer is only second to cervical cancer and

Correspondence to: Professor Hong Xiao, Department of Pharmacy, The Affiliated Brain Hospital of Nanjing Medical University, 264 Guangzhou Road, Nanjing, Jiangsu 210029, P.R. China

E-mail: xhnkyy123@163.com

Key words: ovarian cancer, resistance, adipocytes, carboplatin, angiopoietin-like 4 carcinoma of the corpus uteri, while its mortality rate is ranked the highest among all female-specific malignant tumors, worldwide (2). At present, the most commonly applied treatment for ovarian cancer, in the clinic, is tumor reduction surgery plus platinum-based chemotherapy, in particular carboplatin (3).

Combination treatment has been found to extend the average overall survival (OS) of patients with ovarian cancer and achieve $60-80 \%$ complete tumor remission; nonetheless, some clinical data suggests that only $>30 \%$ patients with ovarian cancer benefit in the long-term from such treatment (4). This may be due to the fact that $>60 \%$ of patients with ovarian cancer develop resistance and recurrence during the medication period, making it difficult to further control cancer deterioration and progression (5). This has become one of the primary obstacles that prevent patients from benefiting from carboplatin and importantly improve their survival.

Currently, the investigation into the mechanism of resistance to carboplatin is primarily restricted to ovarian cancer cells themselves (6), while the tumor cell microenvironment is neglected, which may be the reason for the stagnant research on reversing the resistance to carboplatin. With the increasing support for the associations between obesity with the incidence and mortality rates of female cancer, research into the association between adipocytes and ovarian cancer has become a popular topic in recent years, and the two are associated with each other $(7,8)$. In 2011, a number of studies first reported that adipocytes played a critical part in the development and progression of ovarian cancer. Ovarian cancer cells could absorb the free fatty acids released by the adipocytes (HSL-activated) into the microenvironment to induce the intracellular $\beta$ oxidation processes, such as AMPK activation, and the upregulation of CPT1a and ACOX1 levels, and accelerate tumor cell proliferation and metastasis to the abdominal omentum majus (9). Subsequently, an additional study further identified the molecular basis by which adipocytes induced tumor cell proliferation and invasion. Adipocytes could induce the overexpression and activation of the SIK $2 / \mathrm{p} 85 \alpha-\mathrm{S} 154$ pathway in the cancer cells to mediate the changes in the downstream signal (AMPK/ACC) and the $\beta$ oxidation metabolism pathway (10). Moreover, adipocytes were also revealed to induce the high expression of ovarian cancer cell surface 
receptor CD36, accelerate cell uptake of free fatty acid, and promote cancer proliferation and abdominal metastasis through positive feedback (11).

Based on the status of research, previous studies have discovered that adipocytes may be potentially associated with the resistance of ovarian cancer (12). The co-culture of adipocytes with ovarian cancer cells can activate multiple signal transduction pathways in the cancer cells, such as MyD88/NF-kB/Bcl-xL, but the mechanism by which adipocytes participates in regulating such an effect has not been extensively explored (13). Therefore, based on previous research, the present study aimed to systemically verify the effect of adipocytes on inducing the carboplatin resistance of ovarian cancer using in vivo and in vitro experiments using multiple models, and to explore the underlying molecular mechanisms. The current study could provide a novel theory for reversing the resistance of ovarian cancer in a clinic setting, and into the molecular mechanisms for performing novel antitumor combination treatment in a clinical setting.

\section{Materials and methods}

Cell lines, culture and reagents. The SKOV3 cell line was purchased from American Type Culture Collection, and human pre-adipocytes (HPAds) were purchased from Lonza Group (cat. no. PT-5005), Ltd. The cell lines were routinely detected for mycoplasma contamination. The immortalization, culture and induced differentiation of HPAd was performed with reference to the HPAd culture protocol by Sigma-Aldrich (Merck KGaA). The well-differentiated adipocytes were subsequently used in the adipocyte-associated experiments. The specific reagents used for cell culture were purchased from Sigma-Aldrich (Merck KGaA), and fetal bovine serum (FBS) was purchased from Gibco (Thermo Fisher Scientific, Inc.). The cells were cultured at $37^{\circ} \mathrm{C}$ in a humidified incubator with $5 \% \mathrm{CO}_{2}$.

Nude mouse xenograft model. The animal studies were conducted according to the Guide for the Care and Use of Laboratory Animals of the National Institutes of Health according to the procedures approved by the Research Ethical Committee of Nanjing Medical University. The 5- to 6-week-old female SCID nude mice $(n=104)$ were purchased from the Model Animal Institute of Nanjing University, and fed with either a normal or high-fat diet (HFD) as required by the model. SKOV 3 cells $\left(7 \times 10^{6}\right)$ alone or SKOV 3 cells $\left(7 \times 10^{6}\right)$ combined with the well-differentiated HAds (wild-type or gene knock-down type; $7 \times 10^{6}$ ) were suspended in $200 \mu 1$ Matrigel (BD Biosciences), and injected into the subcutaneous tissues in the right lower limbs of the mice. The subcutaneous xenograft growth was monitored using a vernier caliper, three times a week. The tumor volume was calculated according to the following formula: $0.5 \times \mathrm{LxW}^{2}$ (where $\mathrm{L}$ is the tumor dimension at the longest point, and $\mathrm{W}$ is the tumor dimension at the widest point). Mice were randomly grouped for medication when the xenograft had grown to an average volume of $100 \mathrm{~mm}^{3}$. Following which, the model groups were given $0.9 \%$ normal saline, intraperitoneal injection of carboplatin (Aladdin) once a week $(50 \mathrm{mg} / \mathrm{kg})$, as well as an injection of anti-ANGPTL4 neutralizing antibody (BioXcell) and
C-terminus ANGPTL4 (cANGPTL4; GenScript) into each tumor at $15 \mu \mathrm{g} / \mathrm{ml}$ before the application of chemotherapy. The animals would be deemed as dead when the xenograft volume was $>2,000 \mathrm{~mm}^{3}$. Subsequently, animals were sacrificed using $\mathrm{CO}_{2}$ suffocation (the flow rate of $\mathrm{CO}_{2}, 30 \%$ of the cage volume/min), and the xenografts were obtained and preserved in liquid nitrogen for subsequent molecular biological experiments.

Cell viability detection. In order to detect the sensitivity of ovarian cancer cells (cultured in adipocyte-conditioned medium and adipocyte co-culture, and regulated by multiple small molecular inhibitors, agonists and neutralizing antibodies in vitro) to carboplatin chemotherapy, SKOV3 cells (wild-type or gene-knockdown type) were added into the 96-well plate (Corning, Inc.) at the density of 6,000 cells per well, and the medium was removed $24 \mathrm{~h}$ after cells reached equilibrium. Subsequently, DMEM containing various pathway regulators ( $20 \mu \mathrm{g} / \mathrm{ml}$ cANGPTL $4,48 \mu \mathrm{g} / \mathrm{ml}$ anti-cANGPTL4, $50 \mu \mathrm{M}$ verapamil (Aladdin) and $50 \mathrm{nM}$ A-1155463 (Selleck Chemicals), chemotherapeutics (carboplatin) or adipocyte-conditioned medium was added to the cells; alternatively, the Transwell upper chamber (Corning, Inc.) incubated with adipocytes was combined with the SKOV3 cells for $48 \mathrm{~h}$ of co-culture. All drugs were prepared at appropriate concentrations using DMSO, and equivalent amount of DMSO was present in each well of medium. Subsequently, the CellTiter-Glo reagent (Promega Corporation) was added into the cell medium according to the manufacturer's protocol, and the luminance value was measured using the BioTek Synergy 96-well microplate reader. All experiments were repeated three times.

Reverse transcription-quantitative PCR (RT-qPCR). The total RNA was isolated directly from the cultured cells or xenograft tissues using the Quick-RNA Miniprep kit (cat. no. R1054; Zymo Research Corp.). The HiScript II QRT SuperMix kit (+gDNA wiper) (Vazyme Biotech Co., Ltd.) was used for RT in accordance with the manufacturer's instructions and subsequently qPCR was performed using the SYBR-Green master mix kit (Bio-Rad Laboratories, Inc.). Each reaction was performed under the following thermal cycling conditions: Step $1,95^{\circ} \mathrm{C} / 5 \mathrm{~min}$; step $2,95^{\circ} \mathrm{C} / 20 \mathrm{sec}$; step $3,56^{\circ} \mathrm{C} / 30 \mathrm{sec}$; step $4,72^{\circ} \mathrm{C} / 30 \mathrm{sec}$; steps $2-4$ were repeated for 40 cycles; step $5,72^{\circ} \mathrm{C} / 7 \mathrm{~min}$ and detected using the Bio-Rad CFX384-Touch system (Bio-Rad Laboratories, Inc.). The gene expression level was calculated using the comparative $\mathrm{Ct}$ method, as follows: $\Delta \Delta \mathrm{Ct}=\Delta \mathrm{Ct}_{\text {sample }}-\Delta \mathrm{Ct}_{\text {control, }}$, fold-change $=2^{-\Delta \Delta C q}$ (14). GAPDH was used as the internal reference. The primers used for PCR were as follows: GAPDH forward, 5'-GGAGCGAGATCCCTCCAAAAT-3'; GAPDH reverse, 5'- GGCTGTTGTCATACTTCTCATGG-3'; ABCB1 forward, 5'-GGGATGGTCAGTGTTGATGGA-3'; ABCB1 reverse, 5'-GCTATCGTGGTGGCAAACAATA-3'; ABCC1 forward, 5'-TTACTCATTCAGCTCGTCTTGTC-3'; ABCC1 reverse 5'-CAGGGATTAGGGTCGTGGAT-3'; ABCG2 forward, 5'-CAGGTGGAGGCAAATCTTCGT-3'; ABCG2 reverse, 5'-ACCCTGTTAATCCGTTCGTTTT-3'; Bcl-xL forward, 5'-AATGTCTCAGAGCAACCGGG-3'; and Bcl-xL reverse 5'-CATCCAAACTGCTGCTGTGC-3'. 
Immunohistochemistry (IHC). The formalin-immersed and paraffin-embedded xenograft tissues were sliced into continuous sections at a thickness of $4 \mu \mathrm{m}$ for IHC assay. Subsequently, the sections were subjected to dewaxing and hydration $\left(67^{\circ} \mathrm{C}\right.$ in oven for $2 \mathrm{~h}$, then using xylene and graded ethanol), followed by thermal antigen retrieval using boiling sodium citrate buffer solution ( $\mathrm{pH}$ 6.0). Subsequently, the sections were sealed with $10 \%$ normal FBS for $20 \mathrm{~min}$ at room temperature to remove non-specific binding. Corresponding rabbit-derived primary antibody against ANGPTL4 (1:200; cat. no. ab196746; Abcam) was added at $4^{\circ} \mathrm{C}$ for antigen-antibody binding overnight. Subsequently, the sections were washed with PBS, incubated with goat anti-Rabbit IgG H\&L (HRP) $(1: 1,000$; cat. no. ab6721; Abcam) for $6 \mathrm{~h}$ at room temperature, developed using DAB for 5-10 min, counterstained with hematoxylin for $2 \mathrm{~min}$, and differentiated with $0.1 \%$ hydrochloric acid alcohol rapidly, followed by dehydration (using graded ethanol for $20 \mathrm{~min}$ ), transparentizing (using dimethylbenzene for $10 \mathrm{~min}$ ) and mounting. The IHC results were observed using a light microscope at X100 magnification. IHC images were obtained using the pathological imaging analysis system, and the optical density was analyzed using the Image pro plus software (v6.0; Media Cybernetics, Inc.). Subsequently, five fields of view were randomly selected from each sample for observation, and the expression levels of the target proteins were calculated and analyzed.

Co-immunoprecipitation (co-IP) assay. For co-IP assay, cell lysates, adjusted to $1 \mathrm{mg} / \mathrm{ml}$, were precleared using ANGPTL4 antibody. After gentle rocking overnight at $4^{\circ} \mathrm{C}$, protein $\mathrm{A} / \mathrm{G}$ PLUS-Agarose (Santa Cruz Biotechnology, Inc.) was added to the lysate/antibody mixture and incubated with gentle agitation at $4^{\circ} \mathrm{C}$ for $4 \mathrm{~h}$. Subsequently, the immunoprecipitates were collected using centrifugation $\left(4,000 \mathrm{x} \mathrm{g} ; 4^{\circ} \mathrm{C} ; 4 \mathrm{~min}\right)$ and washed three times with cell lysis buffer (NP-40; Beyotime Institute of Biotechnology), then boiled for 5 min with the same volume of $2 \mathrm{X}$ loading buffer $(62.5 \mathrm{mM}$ Tris- $\mathrm{HCl}$; pH 6.8; $2 \%$ w/v SDS; $10 \%$ glycerol; 50 mM DTT; $0.01 \%$ w/v bromophenol blue). Protein interactions with ANGPTL4 were analyzed using western blot analysis.

Western blot analysis. The intracellular protein was extracted using RIPA lysis buffer (Beyotime Institute of Biotechnology; cat. no. P0013K), and the concentration of total protein or protein after co-immunoprecipitation was quantified using the BSA method. Loading buffer was subsequently added and the mixture was heated to denature the proteins. An equal amount of the protein $(50 \mu \mathrm{g})$, was separated using SDS-PAGE on a $5 \%$ or $10 \%$ gel, and transferred onto polyethylene membranes (Bio-Rad Laboratories, Inc.) using the wet membrane transfer system. Subsequently, the membranes were blocked with 5\% skimmed milk, prepared with the TBS-Tween-20 buffer, and incubated with primary antibody against ANGPTL4 (1:1,000; cat. no. ab2920; Abcam), integrin $\alpha 5 \beta 1$ (1:1,000; cat. no. orb13515; Biorbyt Ltd.), claudin 5 (1:2,000; cat. no. ab131259; Abcam), VE-cadherin (1:1,000; cat. no. 2158; Cell Signaling Technology, Inc.), Bcl-xl (1:1,000; cat. no. ab32370; Abcam), ABCB1 (1:1,000; cat. no. 13342; Cell Signaling Technology, Inc.), ABCC1 (1:1,000; cat. no. 72202; Cell Signaling Technology, Inc.), ABCG2
(1:1,000; cat. no. ab207732; Abcam), $\beta$-actin $(1: 10,000$; cat. no. BS6007M; Bioworld Technology, Inc.), PI3K (1:2,000; cat. no. 4257; Cell Signaling Technology, Inc.), phospho-PI3K (1:1,000; cat. no. 4228; Cell Signaling Technology, Inc.), c-Myc (1:2,000; cat. no. 18583; Cell Signaling Technology, Inc.), phospho-c-Myc (1:1,000; cat. no. 13748; Cell Signaling Technology, Inc.), p65 (1:1,000; cat. no. 8242; Cell Signaling Technology, Inc.), phospho-p65 (1:1,000; cat. no. ab194726; Abcam), Akt (1:2,000; cat. no. 4691; Cell Signaling Technology, Inc.), phospho-Akt (1:2,000; cat. no. 4060; Cell Signaling Technology, Inc.) overnight at $4^{\circ} \mathrm{C}$, whilst avoiding non-specific background. The membranes were then washed and incubated with goat anti-rabbit IgGs-HRP (cat. no. 1:10,000; BS 13278; Bioworld Biotechnology, Inc.) at room temperature for $1 \mathrm{~h}$, and the proteins were detected using the ChemiDoc ${ }^{\mathrm{TM}}$ XRS + system (Bio-Rad Laboratories, Inc.). Finally, the proteins were quantified using the ImageJ software 1.53a (National Institutes of Health). Each sample was repeated three times.

Immunofluorescence detection. All complete medium in the cell supernatant was discarded, and pre-cold $4 \%$ acetone (for $20 \mathrm{~min}$ ) and $0.2 \%$ triton (for $10 \mathrm{~min}$ ) were added for fixation and permeabilization at $4^{\circ} \mathrm{C}$, while $1 \% \mathrm{BSA}$ was added (for $30 \mathrm{~min}$ ) for background sealing. The primary antibody (anti-p65 antibody; 1:1,000; cat. no. ab16502; Abcam) was subsequently added and the samples were incubated overnight at $4^{\circ} \mathrm{C}$, following which the Rhodamine-conjugated fluorescence secondary antibody (1:2,000; cat. no. NB7575; Novus Biologicals, LLC) was added at room temperature. Then, the Actin-Tracker Green (1:100; cat. no. C1033; Beyotime Institute of Biotechnology; for $30 \mathrm{~min}$ ) and Hoechst (cat. no. C1011; Beyotime Institute of Biotechnology; for $5 \mathrm{~min}$ ) stains were incubated at room temperature and away from light orderly, to gradually stain the cytoskeleton and the cell nucleus, respectively. Finally, the sections were mounted with glycerinum, air dried, and observed using the laser scanning confocal microscope (magnification, x200), and images of p65 expression level were obtained.

Short hairpin (sh)RNA knockdown. Predesigned ANGPTL4-knockdown shRNA constructs were purchased from Sigma-Aldrich (Merck KGaA; cat. no. SHCLND-NM_139314_ TRCN0000154688). Vehicle control construct was also provided by Sigma-Aldrich (Merck KGaA; cat. no. SHC016; sequence, 5'-CCGGGCGCGATAGCGCTAATAATTTCT CGAGAAATTATTAGCGCTATCGCGCTTTTT-3'). The sequences for the human ANGPTL4-shRNA was 5'-CCG GGCAGGATATGCTCAGACTCTACTCGAGTAGAGTCT GAGCATATCCTGCTTTTTTG-3'. The plasmid (100 ng/well) was transfected using Lipofectamine 2000 (Thermo Fisher Scientific, Inc.), according to manufacturer's instructions. The protein expression of ANGPTL4 was detected by western blot assay to demonstrate the knockdown was successful.

The TCGA database and data mining. Currently available clinical features and RNAseq data on patients with ovarian cancer $(\mathrm{n}=373)$ was obtained from TCGA (https://cancergenome.nih. gov/). The median ANGPTL4 expression was used as a cut-off to delineate the low vs. high categories. Survival package of 
R (version 3.5.1; https://cran.r-project.org/bin/windows) was used to draw survival curves, followed by log-rank tests to examine the survival deviation.

Statistical analysis. Data are presented as the mean \pm SD of at least three independent experiments. Statistical significance for the growth of xenograft tumors and cell viability were determined by two-way ANOVA (followed by Dunnett's test). All other experiments used a one-way ANOVA with multiple comparisons correction using Dunnett's test to determine significance. $\mathrm{P}<0.05$ was considered to indicate a statistically significant difference.

\section{Results}

Adipocytes could induce the resistance of ovarian cancer cells to carboplatin both in vivo and in vitro. To explore the role of adipocytes in the resistance of ovarian cancer cells to carboplatin, the human SKOV3 ovarian cancer cell line was selected to construct the subcutaneous xenograft model of nude mice, to observe whether HFD would affect the suppression ovarian cancer by carboplatin in vivo. As shown in Fig. 1A, HFD could markedly promote the growth of subcutaneous xenografts in mice compared with that in the model group fed with normal $\operatorname{diet}(\mathrm{P}<0.01)$; the maximum/minimum volume exhibited by a single tumor was $1,189.33 / 524.10 \mathrm{~mm}^{3}$ ). Carboplatin at the dose of $50 \mathrm{mg} / \mathrm{kg}$, administered once a week, markedly suppressed the growth of subcutaneous xenografts in nude mice fed with a normal diet compared with that in the model group fed with normal diet $(\mathrm{P}<0.01)$, but carboplatin showed no marked suppression on the xenograft in mice fed with HFD compared with the model group fed with HFD ( $P>0.05)$. Furthermore, an equivalent concentration of adipocytes was mixed with SKOV3 cells, and subsequently inoculated, subcutaneously, into the nude mice, to observe the direct effect of adipocytes on the resistance of ovarian cancer. As shown in Fig. 1B, similar to mice fed with HFD, the mixed inoculation of adipocytes induced the growth of the subcutaneous xenograft compared with the model group inoculated with SKOV3 alone $(\mathrm{P}<0.01)$; the maximum $/$ minimum volume exhibited by a single tumor was $1,152.81 / 458.18 \mathrm{~mm}^{3}$. Moreover, the adipocyte/SKOV3 mixture reversed the suppression of carboplatin on the xenograft.

Furthermore, two in vitro models were constructed to further verify the role of adipocytes in the resistance of ovarian cancer cells to carboplatin. In the first model, the supernatant was extracted from the well-differentiated adipocytes cultured in vitro as the conditioned medium (CM), to observe whether the CM affects the suppression of carboplatin on ovarian cancer cell viability in vitro. The results shown in Fig. $1 \mathrm{C}$ suggest that compared with carboplatin treatment alone for $48 \mathrm{~h}$, the CM decreased the therapeutic effect of chemotherapeutics on the ovarian cancer cells, and the $\mathrm{IC}_{50}$ values of carboplatin were increased from 100.28 to $155.67 \mu \mathrm{g} / \mathrm{ml}(\mathrm{P}<0.01)$. In the second model, mature adipocytes were first cultured into the upper Transwell chamber for $12 \mathrm{~h}$, following which the chamber was placed into the 96-well plate, to observe the effect of the co-culture system on the chemotherapeutic effects of carboplatin. The results shown in Fig. 1D indicate that the co-culture of adipocytes and SKOV3 decreased the therapeutic effect of carboplatin on tumor cells, resulting in decreased $\mathrm{IC}_{50}$ values from 113.16 to $170.41 \mu \mathrm{g} / \mathrm{ml}(\mathrm{P}<0.01)$. In summary, adipocytes were shown to suppress the therapeutic effects of carboplatin on the ovarian cancer cell line both in vivo and in vitro, thus inducing resistance.

ANTGPL4 released by adipocytes may be important during the induction of resistance. To further explore the mechanism by which adipocytes induce resistance, the genes that were associated with disease stage and survival prognosis in patients with ovarian cancer were investigated using The Cancer Genome Atlas database (TCGA). As shown in Fig. 2A, the expression level of ANGPTL4 was significantly associated with patients with stage I to III of ovarian cancer (373 ovarian cancer samples from the database). The median expression level of ANGPTL4 was selected to divide the samples into high and low expression groups, and there was a significant difference in the OS between the two groups ( $\mathrm{P}<0.05$; Fig. 2B). The statistical result of IHC retrieved from the Human Protein Atlas (HPA) database (https://www.proteinatlas.org/) (Fig. 2C) suggests that ovarian cancer cells did not express ANGPTL4 themselves, while the ANGPTL4 level in ovarian cancer tissues with high adipocyte distribution was markedly higher compared with that in cancer tissues with low adipocyte distribution. Moreover, IHC was performed on the xenograft of each model group from the aforementioned in vivo experiment (Fig. 2D), and the results indicated that the ANGPTL4 levels in subcutaneous xenografts in mice fed with HFD, or inoculated with tumor cells and adipocytes, were markedly higher compared with that in the xenografts in mice fed with normal diet and inoculated with tumor cells alone. The aforementioned results revealed that adipocytes in ovarian cancer tissue were responsible for expressing and releasing ANGPTL4, while the ANGPTL4 expression level was associated with cancer stage and survival prognosis of the patients with ovarian cancer, suggesting that the ANGPTL4 secreted by adipocytes might participate in the genesis and development of ovarian cancer, and may also be involved in the resistance to carboplatin.

To further verify this hypothesis, shRNA interference method was applied to silence the ANGPTL4 level in adipocytes. Subsequently, those cells were inoculated together with SKOV3 cells subcutaneously into the nude mice, to observe the suppression effects of carboplatin on ovarian cancer. As shown in Fig. 2E, silencing of ANGPTL4 in adipocytes reversed the effect of ANGPTL4 on inducing the resistance of ovarian cancer to carboplatin. Similarly, the injection of anti-ANGPTL4 neutralizing antibody into the mixed xenograft (inoculated with the shRNA empty plasmid-transfected adipocytes and ovarian cancer cell line) reversed the resistance of cancer cells to carboplatin (Fig. 2F; the maximum/minimum volume exhibited by a single tumor was $1,418.16 / 244.11 \mathrm{~mm}^{3}$ ). Subsequently, two in vitro cell models were used to verify the important role of ANGPTL4 in the adipocyte-induced resistance. As shown in Fig. $2 \mathrm{G}$ and H, neither the CM of the shANGPTL4 adipocytes, nor the direct co-culture of the shANGPTL4 adipocytes and ovarian cancer cells, could induce the resistance of cancer cells to carboplatin. Furthermore, the addition of anti-ANGPTL4 neutralizing antibody in the adipocyte $\mathrm{CM}$ or the co-culture system could not enhance the $\mathrm{IC}_{50}$ of platinum drugs to SKOV3 cells. 


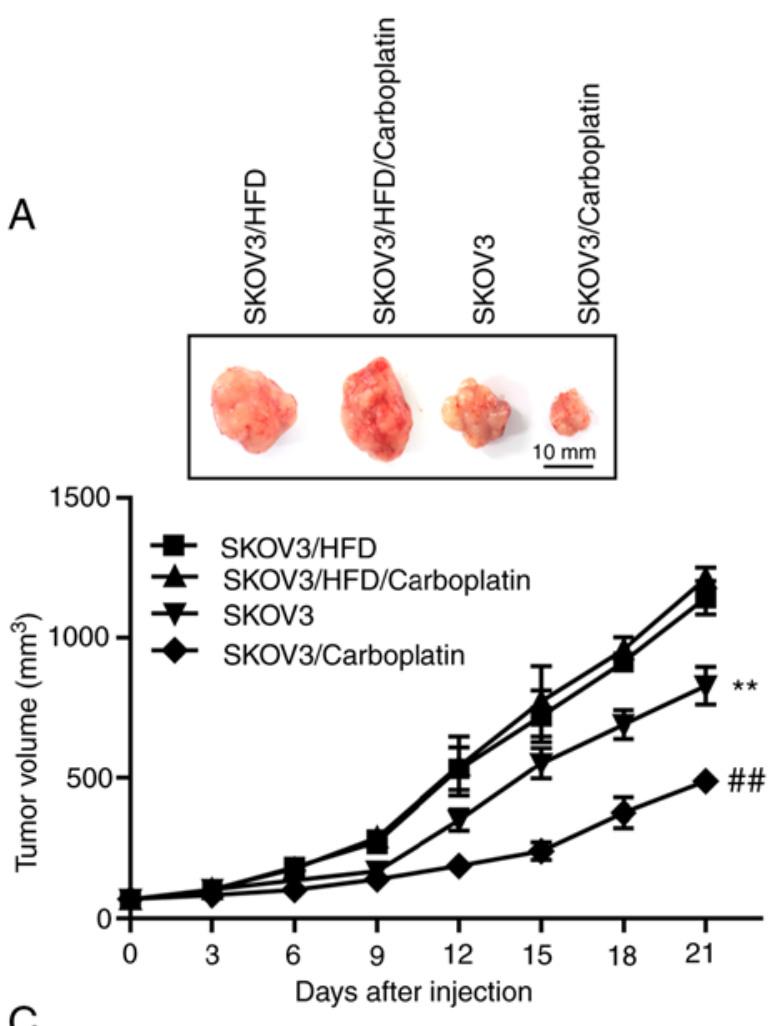

C

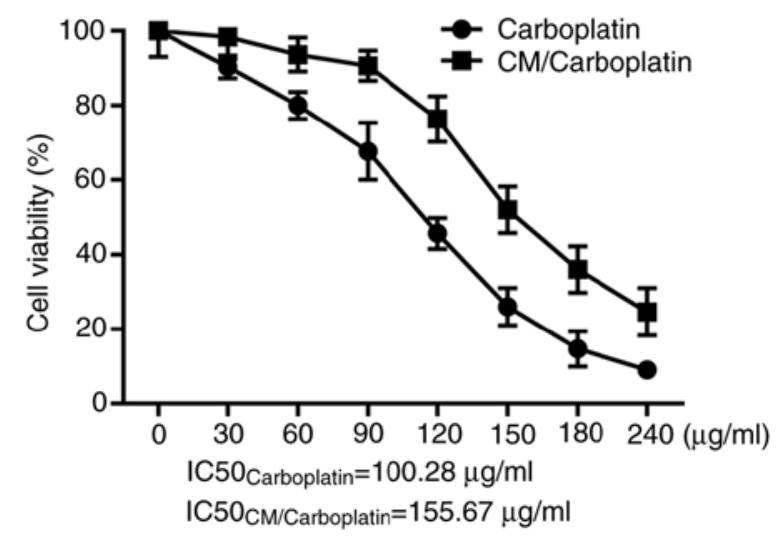

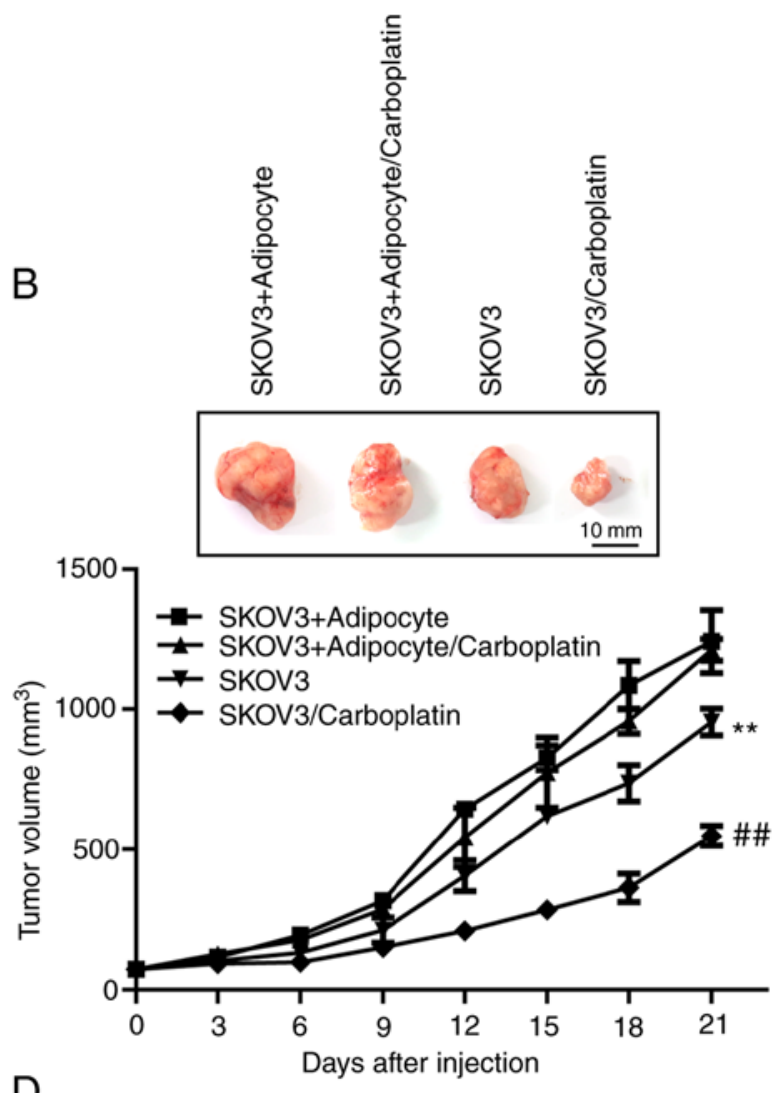

D

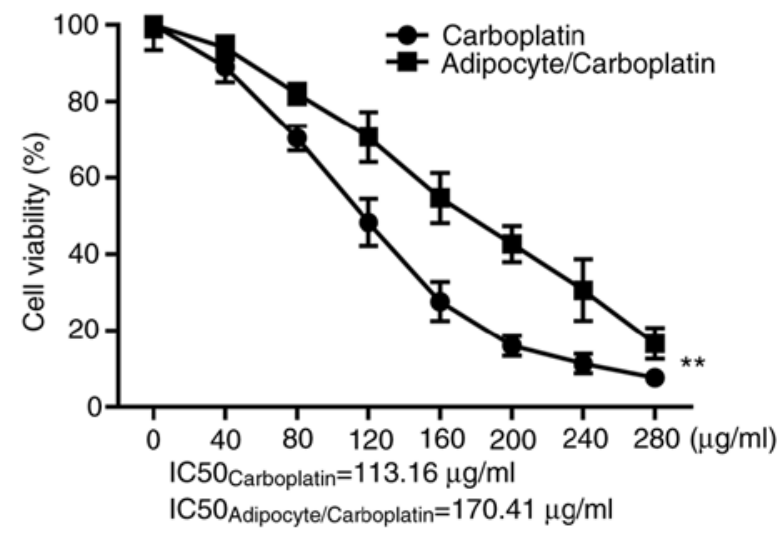

Figure 1. Adipocytes induce the resistance of ovarian cancer cells to carboplatin both in vivo and in vitro. (A) The regulatory effect of HFD on the suppression of carboplatin on SKOV3 cells in vivo. Top, representative images of xenograft tumors in the indicated groups. Bottom, statistical analysis of the growth of xenograft tumors with time. The data are presented as the mean $\pm \mathrm{SD}$. ${ }^{* *} \mathrm{P}<0.01$ vs. SKOV3/HFD. ${ }^{\# \#} \mathrm{P}<0.01$ vs. SKOV3. (B) The direct effect of adipocytes on the resistance of SKOV3 cells to carboplatin in vivo. Top, representative images of xenograft tumors in the indicated groups. Bottom, statistical analysis of the growth of xenograft tumors with time. The data are presented as the mean $\pm \mathrm{SD}$. ${ }^{* *} \mathrm{P}<0.01$ vs. SKOV3 + Adipocyte. ${ }^{* \#} \mathrm{P}<0.01$ vs. SKOV3. (C) The regulatory effect of CM in adipocytes on the suppression of SKOV3 cells viability by carboplatin in vitro. The data are presented as the mean \pm SD. ${ }^{* *} \mathrm{P}<0.01 \mathrm{vs}$. carboplatin. (D) The effect of the co-culture system (mature adipocytes and SKOV3) on the efficacy of carboplatin. The data are presented as the mean \pm SD. ${ }^{* *} \mathrm{P}<0.01$ vs. carboplatin. CM, conditioned medium; HFD, high-fat diet.

Finally, the critical role of ANGPTL4 in the resistance of ovarian cancer was revealed. cANGPTL4 was directly injected into the animals inoculated with SKOV3 cells alone, to observe the influence on the efficacy of carboplatin. As shown in Fig. 2I (the maximum/minimum volume exhibited by a single tumor was $1,323.73 / 458.15 \mathrm{~mm}^{3}$ ), cANGPTL4 suppressed the therapeutic effect of carboplatin, which was similar to that of the co-inoculation of adipocytes and ovarian cancer cells. The in vitro results (Fig. $2 \mathrm{~J}$ ) revealed that the direct addition of cANGPTL4 could also increase the $\mathrm{IC}_{50}$ values of carboplatin from 119.63 to $198.74 \mu \mathrm{g} / \mathrm{ml}(\mathrm{P}<0.01)$, which was similar to those in the adipocyte $\mathrm{CM}$ and the co-culture system.

In summary, the adipocytes in the ovarian cancer microenvironment could release ANGPTL4 to induce the resistance of ovarian cancer cells to first-line chemotherapeutics carboplatin, thus affecting patient survival and prognosis.

ANGPTL4 exerts its downstream effect through binding to the integrin $\alpha 5 \beta 1$ on tumor cell membrane surface. To further explore the molecular mechanism of ANGPTL4, the method 
A

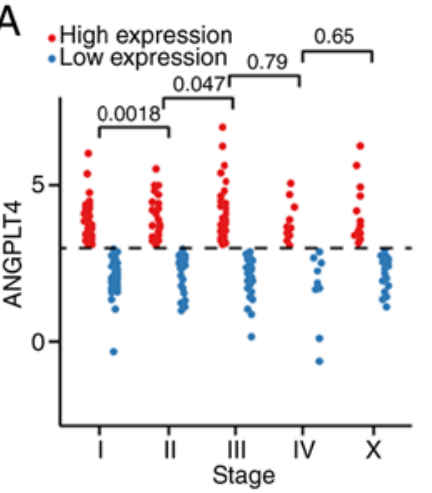

D
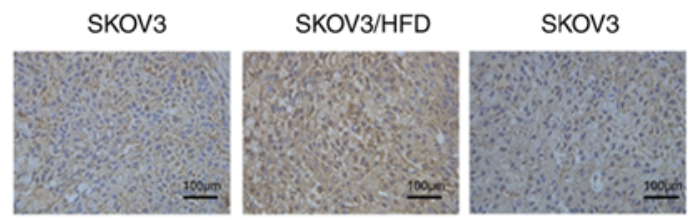

E

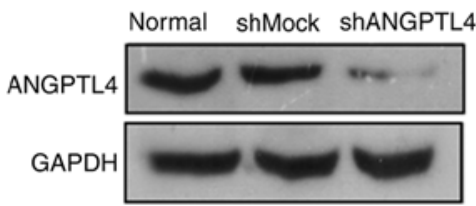

G

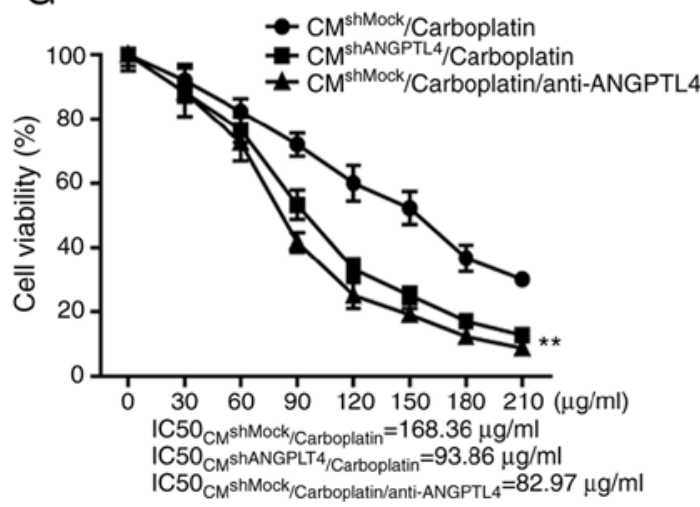

B

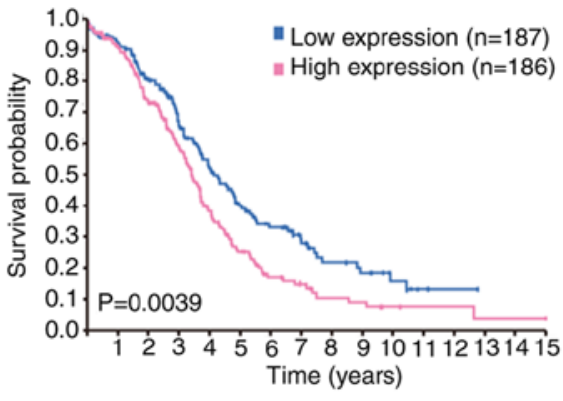

C
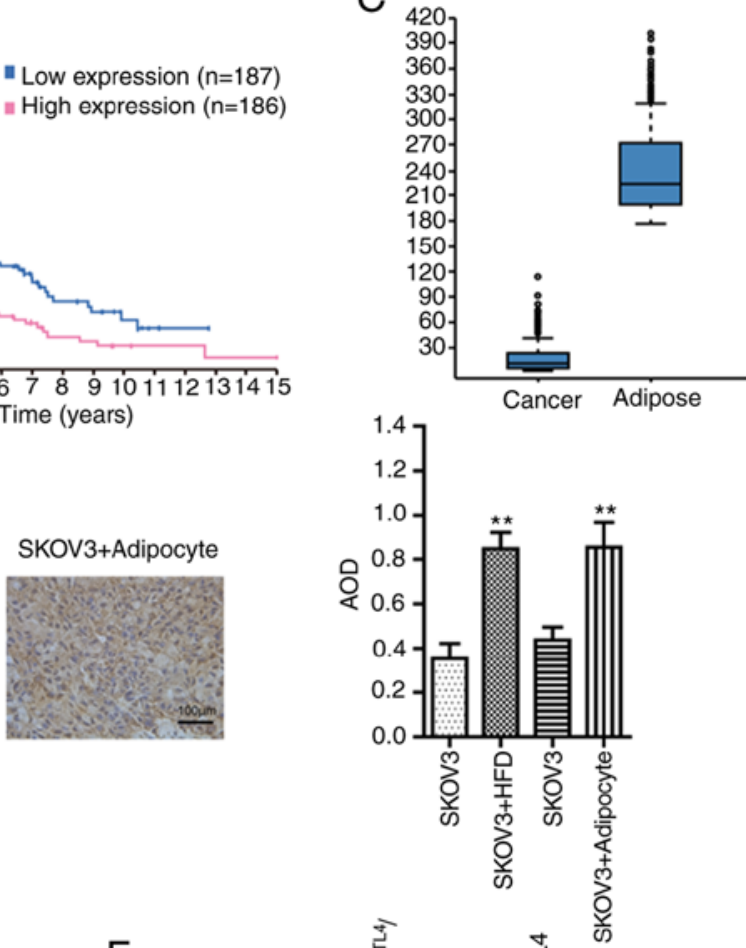

$\mathrm{F}$
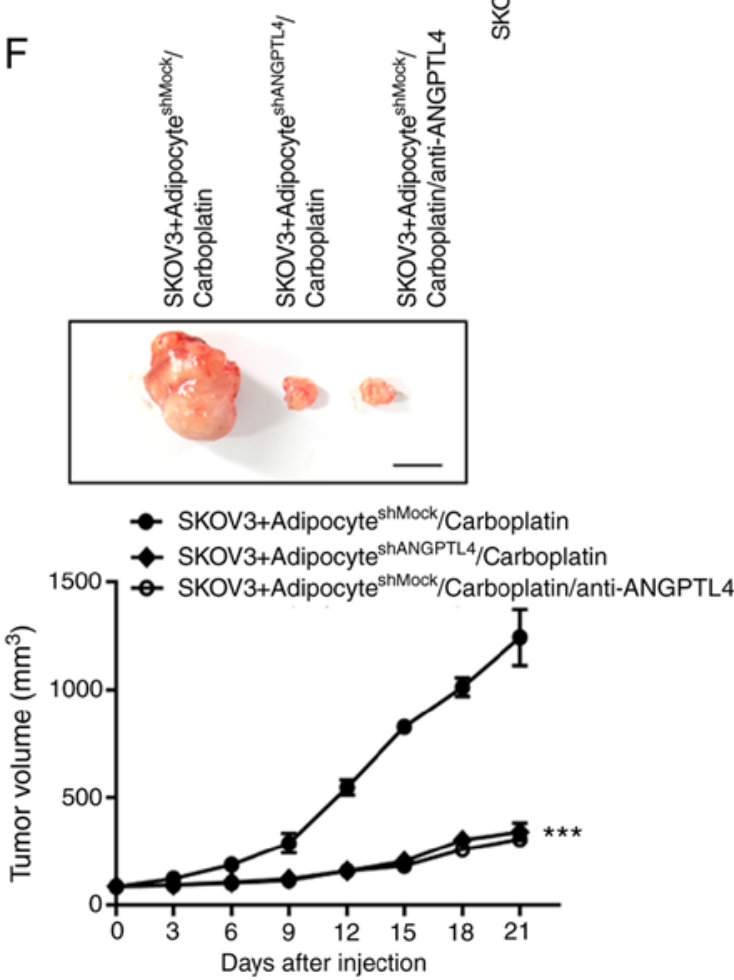

Figure 2. ANTGPL4 released by adipocytes plays an important role during the induction of resistance. (A) The expression level of ANGPTL4 in patients with ovarian cancer at different stages of the disease. (B) The association between the expression level of ANGPTL4 and the overall survival of patients with ovarian cancer $(\mathrm{P}=0.0039)$. (C) The expression levels of ANGPTL4 in cancer cells and adipocytes in the ovarian cancer tissue, respectively. (D) IHC assay was performed on the xenograft of each model group from the initial in vivo experiment to detect the level of ANGPTL4. Left, representative images of IHC in the indicated groups. Right, statistical analysis of IHC data. The data are presented as the mean $\pm \mathrm{SD}$. ${ }^{* *} \mathrm{P}<0.01 \mathrm{vs.} \mathrm{SKOV3}$. (E) The effect of shRNA on ANGPTL4 knockdown in adipocytes demonstrated by western blot assay. (F) The direct effect following silencing of ANGPTL4 in adipocytes on the resistance of SKOV3 cells to carboplatin in vivo. Top, representative images of the xenograft tumors in the indicated groups. Bottom, statistical analysis of the growth of xenograft tumors with time. The data are presented as the mean \pm SD. ${ }^{* * *} \mathrm{P}<0.001$ vs. SKOV3+adipocyte ${ }^{\text {shMock} / c a r b o p l a t i n . ~}(\mathrm{G})$ The direct effect following silencing of ANGPTL4 in adipocytes on the resistance of SKOV3 cells to carboplatin in vitro. The data are presented as the mean $\pm \mathrm{SD}$. ${ }^{* * *} \mathrm{P}<0.01$ vs. CM ${ }^{\text {shMock }} / \mathrm{carboplatin}$

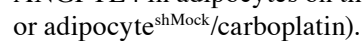

by which the release of ANGPTL4 by adipocytes could associate with tumor cells, was firstly investigated. According to previous research, ANGPTL4 directly binds with VE-cadherin, clauding-5 and integrin $\alpha 5 \beta 1$ on the cell membrane to exert different functions during various pathophysiological processes (15). Therefore, co-IP technique was used to detect 

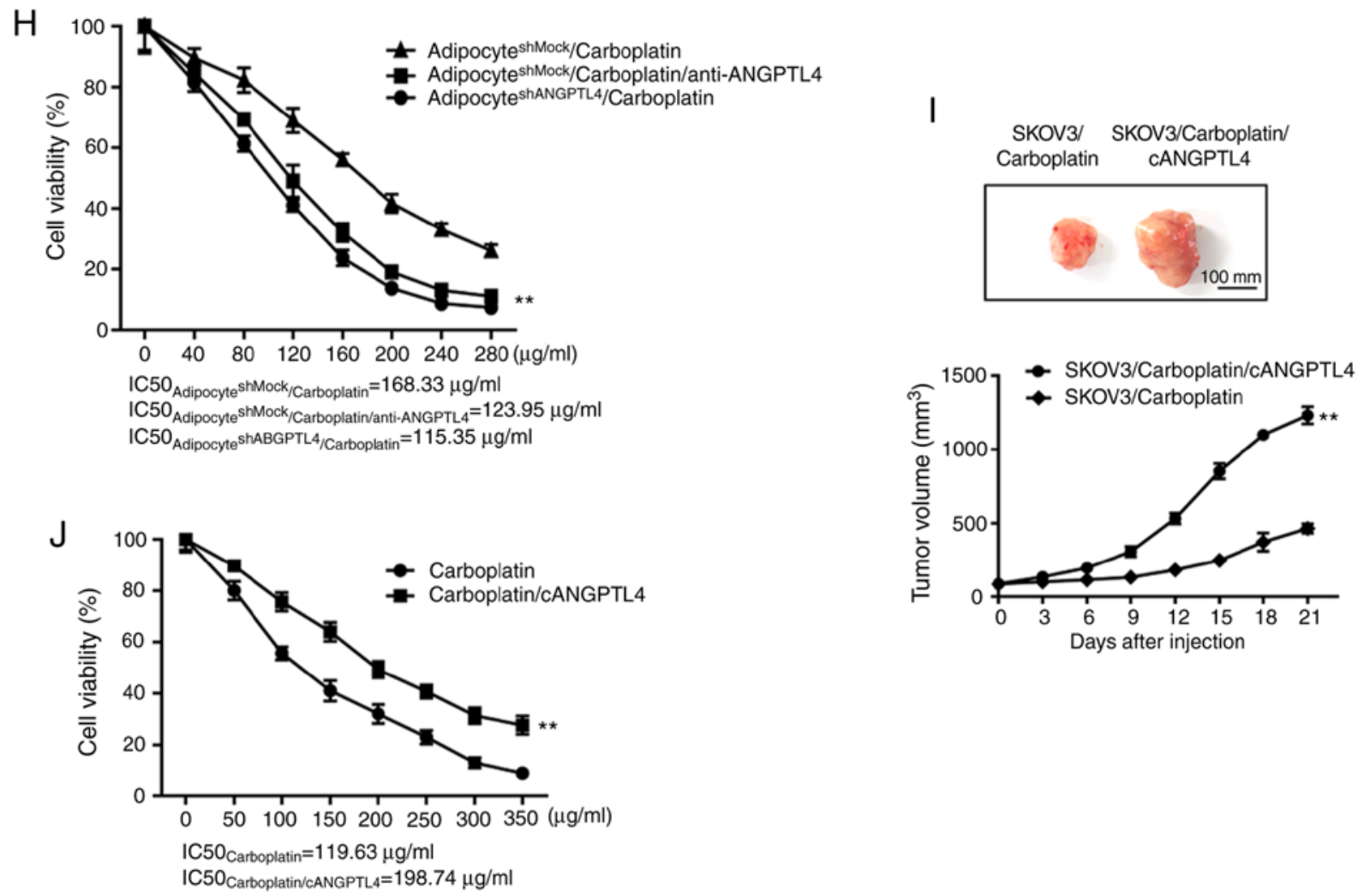

Figure 2. Continued. ANTGPL4 released by adipocytes plays an important role during the induction of resistance. (H) The direct effect following silencing of ANGPTL4 in adipocytes on the resistance of SKOV 3 cells to carboplatin in vitro. The data are presented as the mean $\pm \mathrm{SD}$. ${ }^{* * *} \mathrm{P}<0.01$ vs. $\mathrm{CM}^{\text {shMock}} / \mathrm{carboplatin}$ or adipocyte ${ }^{\text {shMock} / c a r b o p l a t i n) . ~(I) ~ T h e ~ d i r e c t ~ e f f e c t ~ o f ~ c A N G P T L 4 ~ o n ~ t h e ~ r e s i s t a n c e ~ o f ~ S K O V 3 ~ c e l l s ~ i n d u c e d ~ b y ~ a d i p o c y t e s ~ t o ~ c a r b o p l a t i n ~ i n ~ v i v o . ~ T o p, ~ r e p r e-~}$ sentative images of xenograft tumors in the indicated groups. Bottom, statistical analysis of the growth of xenograft tumors with time. The data are presented as the mean $\pm \mathrm{SD}$. ${ }^{* *} \mathrm{P}<0.01$ vs. SKOV3/carboplatin. $(\mathrm{J})$ The effect of cANGPTL4 on the efficacy of carboplatin. The data are presented as the mean \pm SD. ${ }^{* *} \mathrm{P}<0.01$ vs. carboplatin. IHC, immunohistochemistry; ANGPTL4, angiopoietin-like 4; sh, short hairpin; CM, conditioned media.

the binding levels of ANGPTL4 with the aforementioned proteins. As shown in Fig. 3A and B, the co-IP results suggests that ANGPTL4, either in the adipocyte CM or in the SKOV3 co-culture system, had the closest binding with claudin-5 and integrin $\alpha 5 \beta 1$ on the tumor cell membrane surface, which could be reversed by the silencing of ANGPTL4 in adipocytes.

Subsequently, the shRNA interference method was used to explore whether claudin-5 and integrin $\alpha 5 \beta 1$ on the cancer cell surface membrane mediated the ANGPTL4-induced resistance, and the adipocyte $\mathrm{CM}$ or the co-culture with adipocytes was also utilized to observe the suppression of cancer cells by carboplatin. As shown in Fig. 3C-F, compared with SKOV3 cells transfected with the shRNA empty plasmid, silencing of integrin $\alpha 5$ reversed the resistance induced by $\mathrm{CM}$ or co-culture $(\mathrm{P}<0.01)$. On the other hand, silencing of claudin-5 did not reverse the occurrence of resistance $(P>0.05)$. Taken together, the ANGPTL4 released by adipocytes may bind with integrin $\alpha 5 \beta 1$ on the ovarian cancer cell surface to exert its downstream effect on inducing the resistance of cancer cells.

ANGPTL4 induces the expression levels of multiple ATP-dependent transporters and Bcl-xL in tumor cells. According to previous research, the activation of the integrin signaling pathway on the tumor cell membrane might upregulate the expression levels of ATP-dependent transporters and antiapoptosis-associated proteins in cells, accelerate the outward transport of drugs in cancer cells, and resist the drug-induced apoptosis, thus mediating the resistance of cancer cells $(16,17)$. Therefore, western blot analysis and RT-qPCR was performed to confirm that the adipocyte $\mathrm{CM}$, co-culture with adipocytes, and cANGPTL 4 could induce the upregulated expression of $\mathrm{ABCB} 1, \mathrm{ABCC} 1, \mathrm{ABCG} 2$ and Bcl-xL (Fig. 4A and B), which could be reversed by the silencing of ANGPTL4 in adipocytes. Finally, the ATP-dependent transporter inhibitor verapamil and the Bcl-xL inhibitor A-1155463, as well as the adipocyte $\mathrm{CM}$ or the co-culture with adipocytes, were used to observe the influence of these pathway inhibitors on the suppression of carboplatin on cancer cells. The results shown in Fig. 4C and D suggests that either verapamil or A-1155463 could reverse the resistance induced by the $\mathrm{CM}$ or co-culture $(\mathrm{P}<0.01)$. In conclusion, ANGPTL4 secreted by adipocytes could bind with integrin $\alpha 5 \beta 1$ on the ovarian cancer cell membrane to induce the expression of intracellular ATP-dependent transporters and $\mathrm{Bcl}-\mathrm{xL}$, thus inducing the resistance of cancer cells.

Upregulated expression of ATP-dependent transporters and $B c l-x L$ is mediated by $N F-\kappa B$ and c-myc. A previous study investigating protein-protein interactions, using bioinformatics analysis, indicated that the expression of ATP-dependent transporters and $\mathrm{Bcl}-\mathrm{xL}$ was mainly induced by the activation of transcription factors, such as NF- $\mathrm{kB}$ and the upstream kinase pathway (18). To further explore the molecular mechanism by which ANGPTL4 induced the upregulation of intracellular ATP-dependent transporters and Bcl-xL, a series of molecular 


\section{IP ANGPTL4}

A
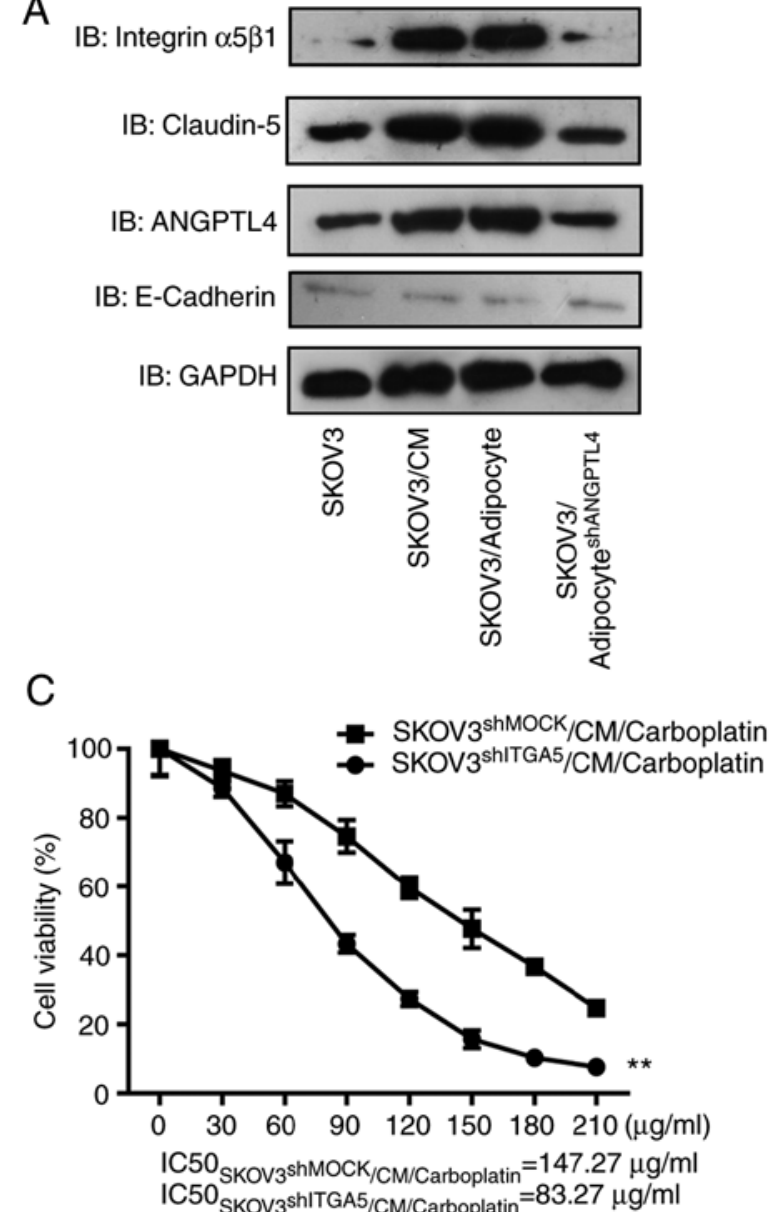

$E$

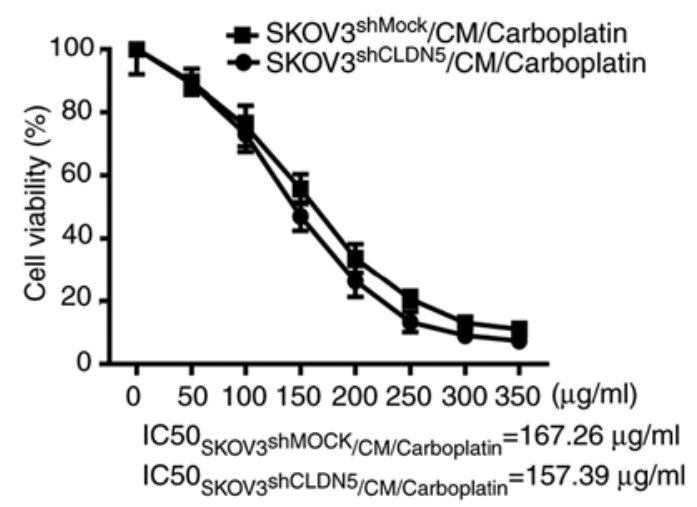

B

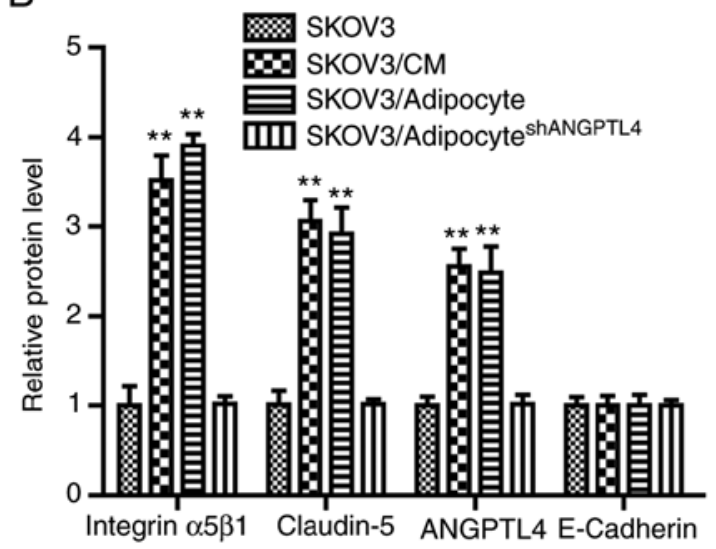

D

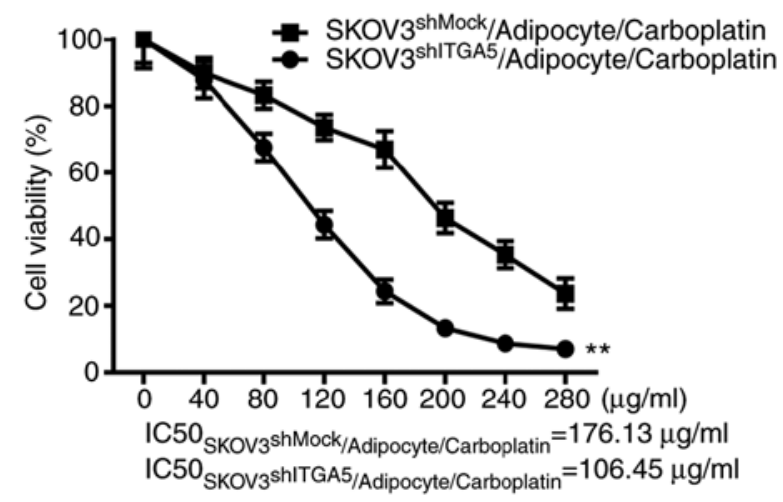

$\mathrm{F}$

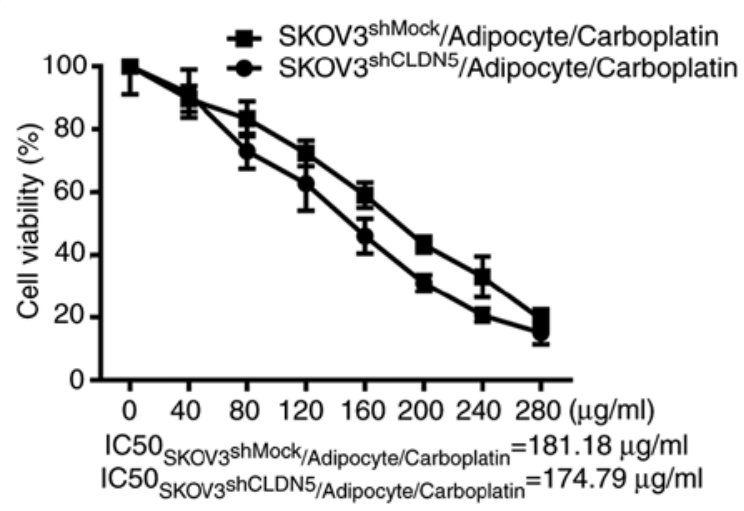

Figure 3. Downstream effect of ANGPTL4 following binding to integrin $\alpha 5 \beta 1$ on surface of the tumor cell membrane. (A) Co-IP was performed and the immunoprecipitates were analyzed using western blot analysis with antibodies against integrin $\alpha 5 \beta 1$, claudin-5, ANGPTL4 and GAPDH. (B) Statistical results of the co-IP assay. The data are presented as the mean $\pm \mathrm{SD} .{ }^{* *} \mathrm{P}<0.01$ vs. SKOV3. (C and $\left.\mathrm{D}\right)$ The regulatory effect following silencing of integrin $\alpha 5 \beta 1$ on the ANGPTL4-induced resistance of SKOV3 cells in vitro. The data are presented as the mean $\pm \mathrm{SD} .{ }^{* *} \mathrm{P}<0.01 \mathrm{vs}$. SKOV3 ${ }^{\text {shMock}} / \mathrm{CM} /{ }^{\circ}$ arboplatin or SKOV3 ${ }^{\text {shMock} / a d i p o c y t e / c a r b o p l a t i n) . ~(E ~ a n d ~ F) ~ T h e ~ r e g u l a t o r y ~ e f f e c t ~ f o l l o w i n g ~ s i l e n c i n g ~ o f ~ c l a u d i n ~} 5$ on the ANGPTL4-induced resistance of SKOV3 cells in vitro. The data are presented as the mean $\pm \mathrm{SD}$. ${ }^{* *} \mathrm{P}<0.01 \mathrm{vs}$. SKOV3 ${ }^{\text {shMock}} / \mathrm{CM} /$ carboplatin $_{\text {or }} \mathrm{SKOV} 3^{\text {shMock}} /$ adipocyte/carboplatin). ANGPTL4, angiopoietin-like 4; Co-IP, co-iummunoprecipitation; sh, short hairpin; CM, conditioned medium.

biological experiments were performed for verification. The results revealed that adipocyte $\mathrm{CM}$, co-culture with adipocytes, and cANGPTL4 could activate the PI3K/Akt pathway in SKOV3 cells, activate the phosphorylation of the downstream c-myc and NF- $\kappa B$ (p65) (Fig. 5A), and induce the accumulation of p65 in the cell nucleus (Fig. 5B). Finally, the Akt inhibitor
MK-2206 and the NF- $\kappa B$ inhibitor (-)-DHMEQ, as well as the adipocyte $\mathrm{CM}$ or the co-culture with adipocytes, were used to observe the influence of these pathway inhibitors on the suppression of carboplatin on cancer cells. The results shown in Fig. 5C and D suggest that either MK-2206 $(1 \mu \mathrm{g} / \mathrm{ml})$ or (-)-DHMEQ $(2.5 \mu \mathrm{g} / \mathrm{ml})$ could reverse the resistance induced 


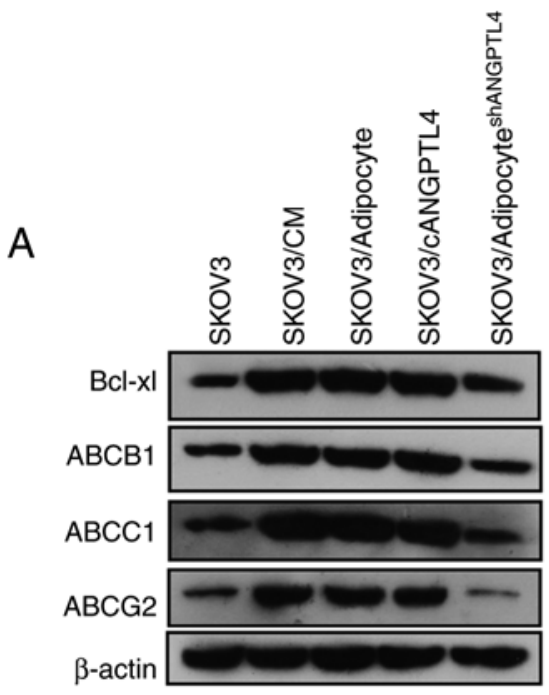

B

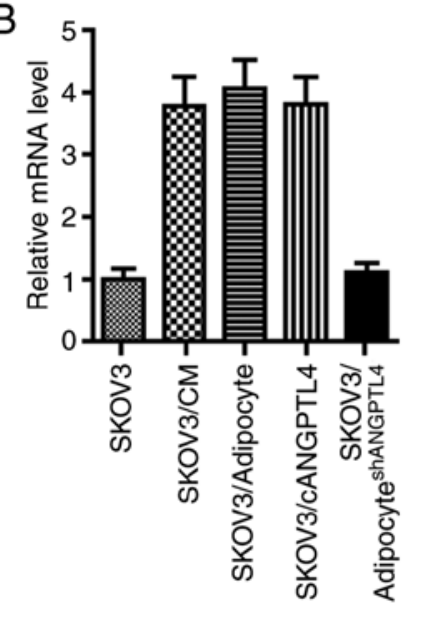

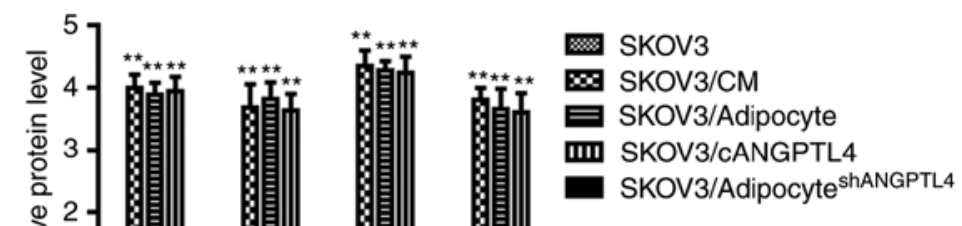

C

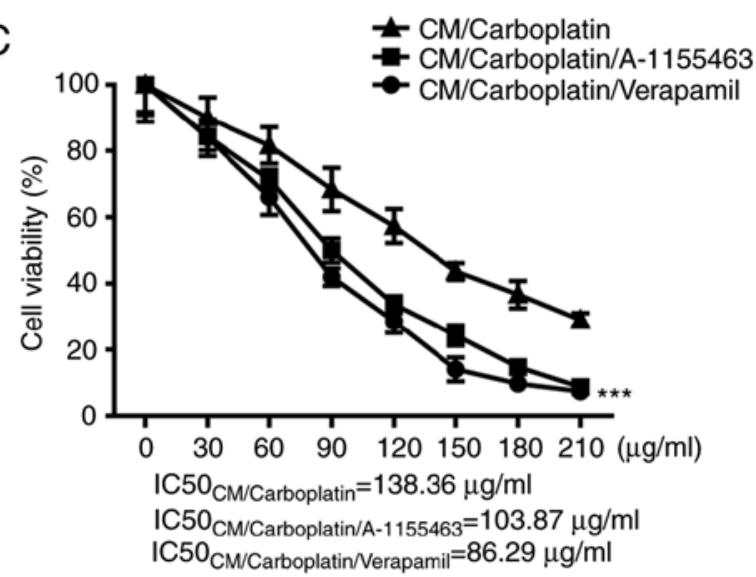

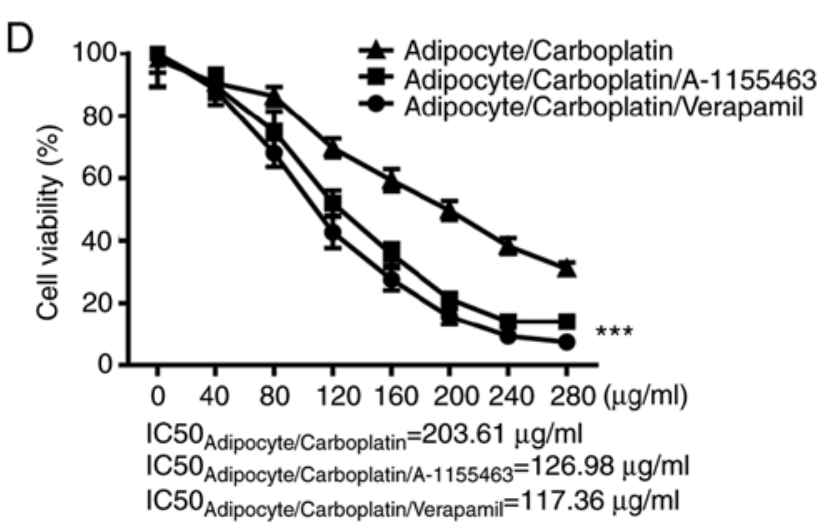

Figure 4. ANGPTL4 induces the expression levels of multiple ATP-dependent transporters and Bcl-xL in tumor cells. (A) The inductive effect of CM or

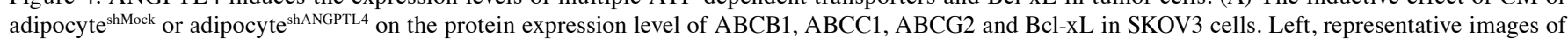
western blot analysis. Right, statistical analysis of western blot assay. The data are presented as the mean $\pm \mathrm{SD} .{ }^{* *} \mathrm{P}<0.01 \mathrm{vs}$. SKOV3. (B) The inducing effect of $\mathrm{CM}$ or adipocyte $\mathrm{shMck}^{\mathrm{s}}$ or adipocyte ${ }^{\text {shANGPTL4 }}$ on the mRNA expression level of ABCB1, ABCC1, ABCG2 and Bcl-xL in SKOV3 cells. The data are presented as the mean $\pm \mathrm{SD}$. ${ }^{* *} \mathrm{P}<0.01$ vs. SKOV3. (C and D) The effect of verapamil and A-1155463 on the efficacy of the chemotherapeutics. The data are presented as the mean $\pm \mathrm{SD} .{ }^{* * *} \mathrm{P}<0.001$ vs. CM/carboplatin or adipocyte/carboplatin). ANGPTL4, angiopoietin-like 4; CM, conditioned medium; sh, short hairpin.

by the CM or co-culture $(\mathrm{P}<0.01)$. In summary, ANGPTL4 secreted by adipocytes could bind with integrin $\beta 1$ on cell membrane of ovarian cancer, activate kinases (PI3K/Akt), stimulate nuclear import of NF- $\kappa \mathrm{B}$, and induce the expression of intracellular ATP-dependent transporters and Bcl-xL, thus leading to the occurrence of ovarian cancer resistance to carboplatin.

\section{Discussion}

With the improved understanding of ovarian cancer biology, worldwide research has identified several molecular mechanisms regarding the resistance of tumor cells to platinum chemotherapeutics, in particular carboplatin. For example, the overexpression or activation of the mitochondrial enzyme 

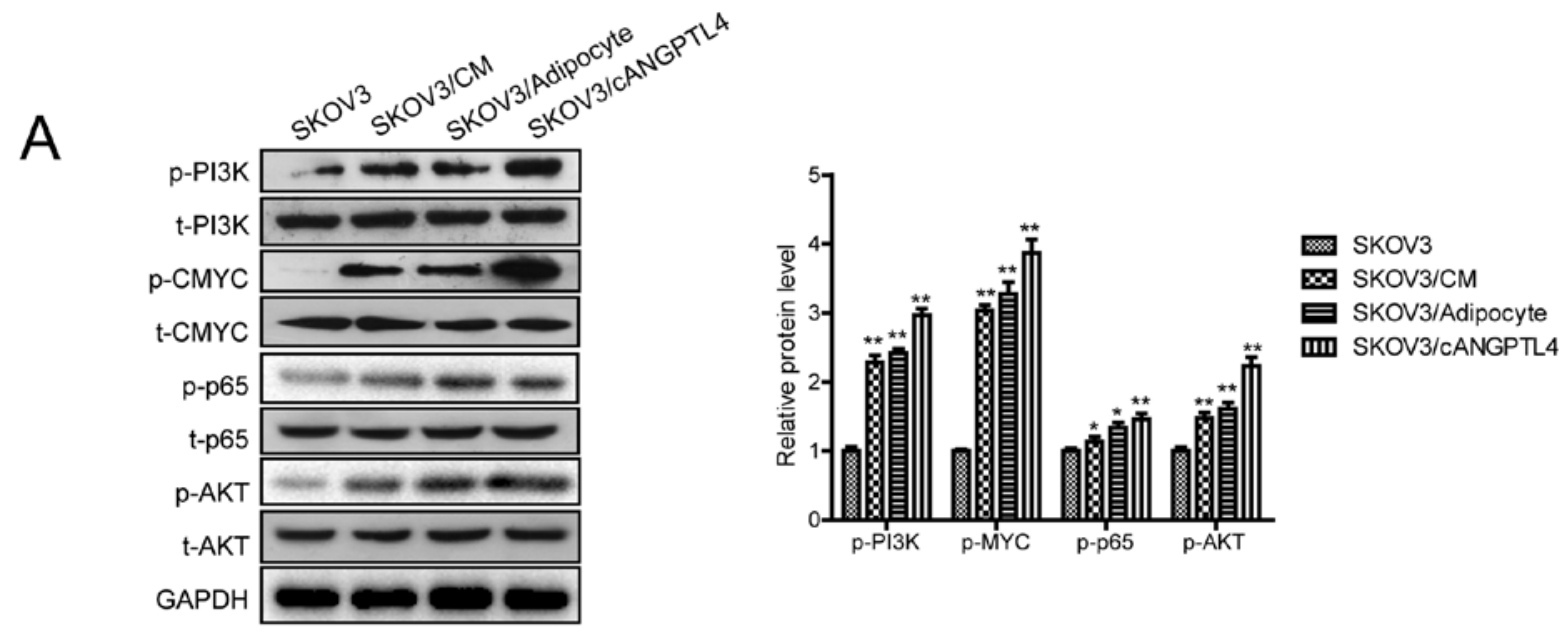

B

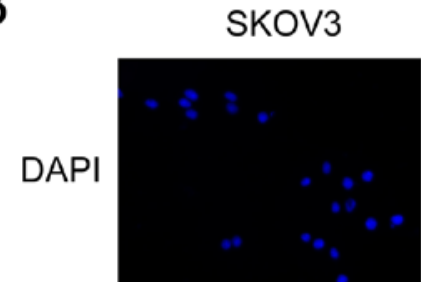

\section{$\mathrm{SKOV} 3 / \mathrm{CM}$}

SKOV3/Adipocyte SKOV3/cANGPTL4
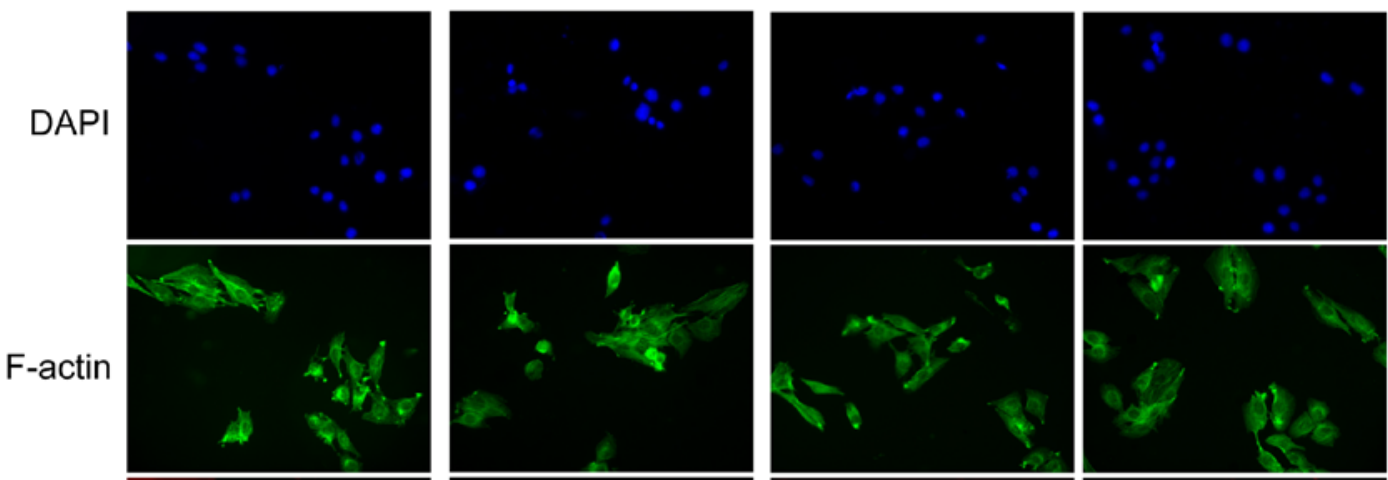

p65
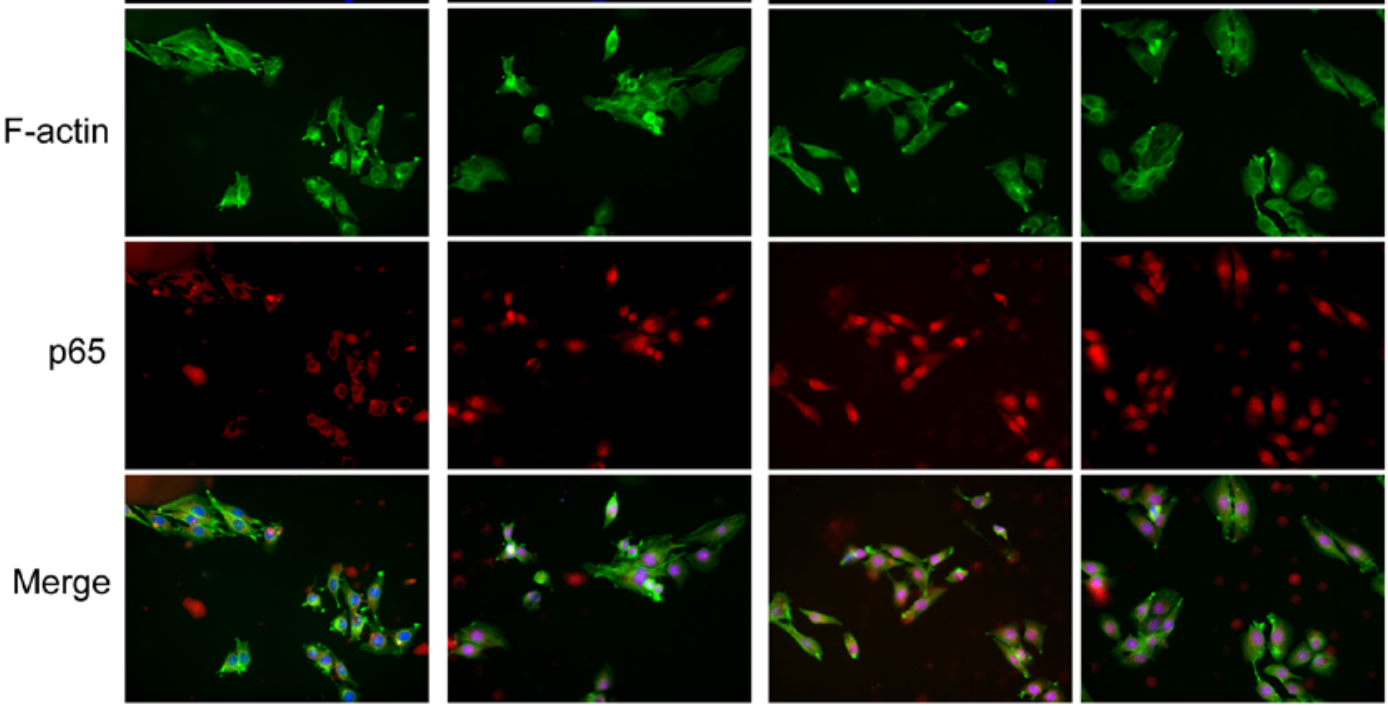

C

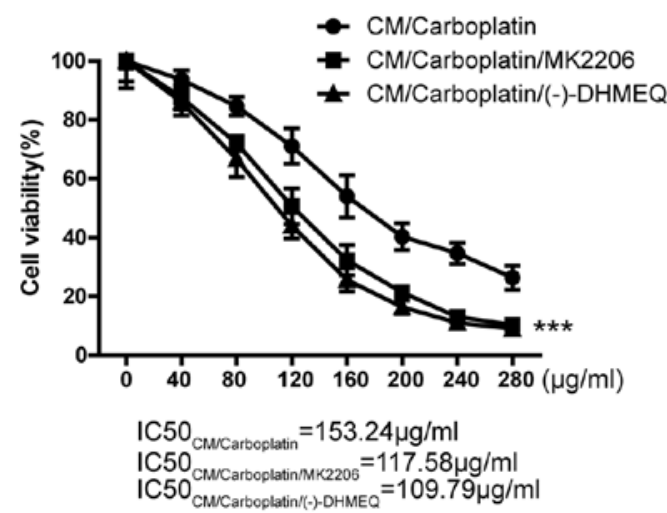

D

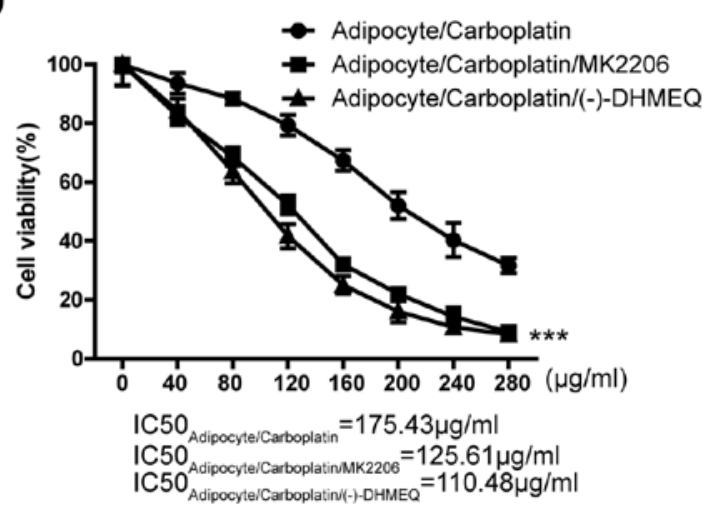

Figure 5. Upregulated expression of ATP-dependent transporters and Bcl-xL is mediated by c-myc and and NF-кB. (A) The effect of CM, adipocytes, and cANGPTL4 on the activity of Akt, PI3K, p65 and c-myc in SKOV3 cells. Left, representative images of western blot analysis. Right, statistical analysis of western blot analysis. The data are presented as the mean $\pm \mathrm{SD}$. ${ }^{*} \mathrm{P}<0.05,{ }^{* *} \mathrm{P}<0.01$ vs. SKOV3. (B) The effect of CM, adipocytes, and cANGPTL4 on the nuclear localization of p65 in SKOV3 cells. (C and D) The effect of MK-2206 and (-)-DHMEQ on the efficacy of the chemotherapeutics. The data are presented as the mean $\pm \mathrm{SD} .{ }^{* * * *} \mathrm{P}<0.001$ vs. CM/carboplatin or adipocyte/carboplatin. ANGPTL4, angiopoietin-like 4; CM, conditioned medium. 
(ATPase in the ABC family) resulted in the reduced intracellular accumulation of platinum drugs (19); the intracellular nucleophilic molecules can bind with platinum drugs to play a role as the platinum separant (20); activation of processes, such as nucleotide excision repair (21), BRCA1/2 mutation (22) and PMS2 deletion (23); the formation of epithelial-mesenchymal transition in ovarian cancer cells (24), autophagy resistance of ovarian cancer cells (25), and epigenetic changes (26). Based on this, basic and clinical therapeutic experiments have been performed using westernized medicine combined with platinum drugs. However unsatisfactory results have been obtained, and the long-term combined treatment will increase the risk of systemic toxic and side effects $(27,28)$. Therefore, the issue of reversing resistance to platinum drugs, improve the anti-ovarian cancer effects in a more durable manner, and extending patient survival, has attracted attention from clinicians and researchers.

An increasing number of studies have found associations between obesity and the incidence and mortality rates of female-associated cancer, and research into the association between adipocytes and ovarian cancer has become a hotspot in recent years, which has revealed that the two are significantly associated with each other. Typically, adipocytes have been found to be involved in the genesis, development, and malignant transformation of ovarian cancer (7). On this basis, it was hypothesized that adipocytes might participate in and induce the resistance of ovarian cancer cells to platinum drugs. Therefore, in the present study, the in vivo and in vitro models were used to verify that adipocytes could weaken the suppression of the ovarian cancer first-line therapeutic, carboplatin, on SKOV3, promote the growth of the xenograft, weaken the therapeutic effect of carboplatin, and induce the occurrence of resistance.

Subsequently, the large sample databases (TCGA and HBA) were used for bioinformatics investigation, to identify key molecular targets by which adipocytes regulate the resistance of ovarian cancer cells. As shown in the results, a secretory glycosylated protein, ANGPTL4, which can be generally split into two active peptides, was found. The N-terminal is an effective lipoprotein lipase inhibitor, which can regulate lipid composition and energy homeostasis; while the C-terminal primarily participates in wound healing, regulation of vascular permeability and angiogenesis (29,30). ANGPTL4 has been verified in a previous study to participate in pathological angiogenesis in the microenvironment of cancer types rich in adipocytes, such as breast cancer and melanoma, and its high expression is markedly associated with poor prognosis (31). In the present study, analysis of TCGA database suggested that, the expression level of ANGPTL4 was positively associated with cancer stage and survival of patients with ovarian cancer. Furthermore, analysis of HBA database indicated that ovarian cancer cells themselves did not express ANGPTL4, and ANGPTL4 in ovarian cancer tissues was primarily released by adipocytes. In subsequent experiments, it was revealed that ANGPTL4 in adipocytes was the key target protein inducing the resistance of ovarian cancer through forward and backward validation means.

Membrane proteins, such as integrin and claudin are highly expressed and excessively activated in ovarian cancer cells, which have been proven to participate in multiple pathological processes during the development and progression of ovarian cancer, including resistance and abdominal omentum majus metastasis $(32,33)$. In the present study, co-IP techniques were used to verify that the ANGPTL4 released by adipocytes could primarily bind with integrin $\alpha 5 \beta 1$ and claudin-5 in the protein membrane, and induce the resistance of ovarian cancer, which was primarily mediated by integrin $\alpha 5 \beta 1$. In subsequent experiments, it was discovered that integrin $\alpha 5 \beta 1$ primarily activated the downstream kinase pathway to promote the activation of $\mathrm{c}-\mathrm{myc}$ and $\mathrm{NF}-\kappa \mathrm{B}$, which could thereby upregulate the expression of ATP-dependent transporters and the anti-apoptotic protein $\mathrm{Bcl}-\mathrm{xL}$, accelerating the outward transport of chemotherapeutics from cancer cells, inducing the resistance of cells to apoptosis, and finally induce drug resistance.

\section{Acknowledgements}

Not applicable.

\section{Funding}

Not applicable.

\section{Availability of data and material}

We declare that materials described in the manuscript, including all relevant data, will be freely available to any scientist wishing to use them for non-commercial purposes, without breaching participant confidentiality.

\section{Authors' contributions}

SZ and HX were involved in the conception and design of the study. HX guided the cell biology and animal experiments, and was responsible for the whole project. RW performed the bioinformatics data collection and analysis, and figure processing. SZ contributed to the cell biology experiments, animal experiments and project management. SZ and RW drafted and edited the manuscript; and HX critically revised the manuscript for important intellectual content. All authors confirmed and approved the final manuscript.

\section{Ethics approval and consent to participate}

The animal studies were conducted according to the Guide for the Care and Use of Laboratory Animals of the National Institutes of Health, according to the procedures approved by the Research Ethical Committee of Nanjing Medical University.

\section{Patient consent for publication}

Not applicable.

\section{Competing interests}

The authors declare that they have no competing interests.

\section{References}

1. Torre LA, Trabert B, DeSantis CE, Miller KD, Samimi G, Runowicz CD, Gaudet MM, Jemal A and Siegel RL: Ovarian cancer statistics, 2018. CA Cancer J Clin 68: 284-296, 2018. 
2. Bray F, Ferlay J, Soerjomataram I, Siegel RL, Torre LA and Jemal A: Global cancer statistics 2018: GLOBOCAN estimates of incidence and mortality worldwide for 36 cancers in 185 countries. CA Cancer J Clin 68: 394-424, 2018.

3. Burges A and Schmalfeldt B: Ovarian cancer: Diagnosis and treatment. Dtsch Arztebl Int 108: 635-641, 2011.

4. Fotopoulou C: Limitations to the use of carboplatin-based therapy in advanced ovarian cancer. EJC Suppl 12: 13-16, 2014.

5. Agarwal R and Kaye SB: Ovarian cancer: Strategies for overcoming resistance to chemotherapy. Nat Rev Cancer 3: 502-516, 2003.

6. Damia $\mathrm{G}$ and Broggini M: Platinum resistance in ovarian cancer: Role of DNA repair. Cancers (Basel) 11: 119, 2019.

7. John B, Naczki C, Patel C, Ghoneum A, Qasem S, Salih Z and Said N: Regulation of the bi-directional cross-talk between ovarian cancer cells and adipocytes by SPARC. Oncogene 38: 4366-4383, 2019.

8. Tang J, Pulliam N, Ozes A, Buechlein A, Ding N, Keer H, Rusch D, O'Hagan H, Stack MS and Nephew KP: Epigenetic targeting of adipocytes inhibits High-Grade serous ovarian cancer cell migration and invasion. Mol Cancer Res 16: 1226-1240, 2018.

9. Nieman KM, Kenny HA, Penicka CV, Ladanyi A, Buell-Gutbrod R, Zillhardt MR, Romero IL, Carey MS, Mills GB, Hotamisligil GS, et al: Adipocytes promote ovarian cancer metastasis and provide energy for rapid tumor growth. Nat Med 17: 1498-1503, 2011.

10. Miranda F, Mannion D, Liu S, Zheng Y, Mangala LS, Redondo C, Herrero-Gonzalez S, Xu R, Taylor C, Chedom DF, et al: Salt-inducible kinase 2 couples ovarian cancer cell metabolism with survival at the Adipocyte-Rich metastatic niche. Cancer Cell 30: 273-289, 2016

11. Ladanyi A, Mukherjee A, Kenny HA, Johnson A, Mitra AK, Sundaresan S, Nieman KM, Pascual G, Benitah SA Montag A, et al: Adipocyte-induced CD36 expression drives ovarian cancer progression and metastasis. Oncogene 37: 2285-2301, 2018

12. Nowicka A, Marini FC, Solley TN, Elizondo PB, Zhang Y, Sharp HJ, Broaddus R, Kolonin M, Mok SC, Thompson MS, et al: Human omental-derived adipose stem cells increase ovarian cancer proliferation, migration, and chemoresistance. PLoS One 8: e81859, 2013.

13. Cardenas C, Montagna MK, Pitruzzello M, Lima E, Mor G and Alvero AB: Adipocyte microenvironment promotes $\mathrm{Bcl}_{\mathrm{x} 1}$ expression and confers chemoresistance in ovarian cancer cells. Apoptosis 22: 558-569, 2017.

14. Schmittgen TD and Livak KJ: Analyzing real-time PCR data by the comparative C(T) method. Nat Protoc 3: 1101-1108, 2008.

15. Huang RL, Teo Z, Chong HC, Zhu P, Tan MJ, Tan CK, Lam CR, Sng MK, Leong DT, Tan SM, et al: ANGPTL4 modulates vascular junction integrity by integrin signaling and disruption of intercellular VE-cadherin and claudin-5 clusters. Blood 118 : 3990-4002, 2011.

16. Wang WW, Wang YB, Wang DQ, Lin Z and Sun RJ: Integrin beta-8 (ITGB8) silencing reverses gefitinib resistance of human hepatic cancer HepG2/G cell line. Int J Clin Exp Me 8: 3063-3071, 2015

17. Santos AR, Corredor RG, Obeso BA, Trakhtenberg EF, Wang Y, Ponmattam J, Dvoriantchikova G, Ivanov D, Shestopalov VI, Goldberg JL, et al: $\beta 1$ integrin-focal adhesion kinase (FAK) signaling modulates retinal ganglion cell (RGC) survival. PLoS One 7: e48332, 2012.

18. Lim MMK, Wee JWK, Soong JC, Chua D, Tan WR, Lizwan M, Li Y, Teo Z, Goh WWB, Zhu P and Tan NS: Targeting metabolic flexibility via angiopoietin-like 4 protein sensitizes metastatic cancer cells to chemotherapy drugs. Mol Cancer 17: 152, 2018.
19. Yoshida H, Teramae M, Yamauchi M, Fukuda T, Yasui T, Sumi T, Honda K and Ishiko O: Association of copper transporter expression with platinum resistance in epithelial ovarian cancer. Anticancer Res 33: 1409-1414, 2013.

20. Surowiak P, Materna V, Maciejczyk A, Pudełko M, Markwitz E, Spaczyński M, Dietel M, Zabel M and Lage H: Nuclear metallothionein expression correlates with cisplatin resistance of ovarian cancer cells and poor clinical outcome. Virchows Arch 450: 279-285, 2007.

21. Liu J, Zhang L, Mao P, Jiang G, Liu L, Wang J, Yang W, Owusu L and Li W: Functional characterization of a novel transcript of ERCC1 in chemotherapy resistance of ovarian cancer. Oncotarget 8: 85759-85771, 2017.

22. Ang JE, Gourley C, Powell CB, High H, Shapira-Frommer R, Castonguay V, De Greve J, Atkinson T, Yap TA, Sandhu S, et al: Efficacy of chemotherapy in BRCA1/2 mutation carrier ovarian cancer in the setting of PARP inhibitor resistance: A multi-institutional study. Clin Cancer Res 19: 5485-5493, 2013.

23. Helleman J, van Staveren IL, Dinjens WN, van Kuijk PF, Ritstier K, Ewing PC, van der Burg ME, Stoter G and Berns EM: Mismatch repair and treatment resistance in ovarian cancer. BMC Cancer 6: 201, 2006.

24. Haslehurst AM, Koti M, Dharsee M, Nuin P, Evans K, Geraci J, Childs T, Chen J, Li J, Weberpals J, et al: EMT transcription factors snail and slug directly contribute to cisplatin resistance in ovarian cancer. BMC Cancer 12: 91, 2012.

25. You Y, Bi FF, Jiang Y, Xu YT, An YY, Li D and Yang Q: BRCA1 affects the resistance and stemness of SKOV3-derived ovarian cancer stem cells by regulating autophagy. Cancer Med 8: 656-668, 2019.

26. Borley $\mathbf{J}$ and Brown R: Epigenetic mechanisms and therapeutic targets of chemotherapy resistance in epithelial ovarian cancer. Ann Med 47: 359-369, 2015.

27. Lee JM, Hays JL, Annunziata CM, Noonan AM, Minasian L, Zujewski JA, Yu M, Gordon N, Ji J, Sissung TM, et al: Phase I/Ib study of olaparib and carboplatin in BRCA1 or BRCA2 mutation-associated breast or ovarian cancer with biomarker analyses. J Natl Cancer Inst 106: dju089, 2014.

28. Musa F, Alard A, David-West G, Curtin JP, Blank SV and Schneider RJ: Dual mTORC1/2 inhibition as a novel strategy for the resensitization and treatment of platinum-resistant ovarian cancer. Mol Cancer Ther 15: 1557-1567, 2016.

29. Lei X, Shi F, Basu D, Huq A, Routhier S, Day R and Jin W: Proteolytic processing of angiopoietin-like protein 4 by proprotein convertases modulates its inhibitory effects on lipoprotein lipase activity. J Biol Chem 286: 15747-15756, 2011.

30. Zhu P, Goh YY, Chin HF, Kersten S and Tan NS: Angiopoietin-like 4: A decade of research. Biosci Rep 32: 211-219, 2012.

31. Tan MJ, Teo Z, Sng MK, Zhu P and Tan NS: Emerging roles of angiopoietin-like 4 in human cancer. Mol Cancer Res 10: 677-688, 2012.

32. Kobayashi M, Sawada K and Kimura T: Potential of integrin inhibitors for treating ovarian cancer: A literature review. Cancers (Basel) 9: 83, 2017.

33. Bose CK and Mukhopadhyay A: Claudin and ovarian cancer. J Turk Ger Gynecol Assoc 11: 48-54, 2010.

(i) $\odot$ This work is licensed under a Creative Commons Attribution-NonCommercial-NoDerivatives 4.0 International (CC BY-NC-ND 4.0) License. 